\title{
Complete absence of rib ossification, micrognathia and ear anomalies: extreme expression of cerebro-costo-mandibular syndrome?
}

\author{
R aoul CM Hennekam ${ }^{1}$ and R oel Goldschmeding ${ }^{2}$ \\ ${ }^{1}$ Institute for H uman G enetics and D epartment of Pediatrics \\ ${ }^{2} \mathrm{D}$ epartment of Pathology, A cademic M edical Center, A msterdam, The N etherlands
}

\begin{abstract}
We describe a newborn with complete absence of ossification of the ribs, extreme micrognathia, absence of external ear canals and the inner ears, and diminished mobility in the upper extremities. It is suggested that this represents an unusually severe expression of the cerebro-costo-mandibular syndrome. Some developmental genes that may have played a role in the pathogenesis are briefly reviewed.
\end{abstract}

Keywords: Cerebro-costo-mandibular syndrome; ribs, absence of; goosecoid; Myf5

\section{Introduction}

The cerebro-costo-mandibular syndrome (CCMS) is an infrequently described condition, consisting of severe micrognathia, posterior rib-gap defects, and developmental delay. ${ }^{1}$ The latter is thought to be secondary to perinatal respiratory distress and hypoxia, caused by the glossoptosis and the flail chest, which made $M$ einecke et al suggest that costo-mandibular syndrome might be a better designation. ${ }^{2}$ Fifty cases have been described so far worldwide. ${ }^{3}$

$\mathrm{H}$ ere we report on a newborn with features fitting CCMS, although in an unusually severe expression, and hypothesize on the molecular background of the syndrome.

Correspondence: Dr R CM H ennekam, Institute for H uman G enetics, A cademic M edical Center, M eibergdreef 15, 1105 A Z A msterdam, The Netherlands

R eceived 20 J une 1997; revised 8 September 1997; accepted 24 September 1997

\section{Case Report}

The proband was the second-born child of a healthy, non-consanguineous parents. Their first child, a boy, was normal. The pregnancy was complicated by polyhydramnios: sonography showed a breech position and retrognathia, but no other abnormalities. The mother denied exposure to any known teratogenic agent. The delivery started spontaneously at 34 weeks, 5 days. The newborn girl weighed $1600 \mathrm{~g}$ (5th centile), length $43 \mathrm{~cm}$ (15th centile), and head circumference $31 \mathrm{~cm}$ (25th centile). Multiple dysmorphic features were noted immediately: downward slanting palpebral fissures, high nasal bridge, small mouth, extremely high and narrow palate, micrognathia, and atretic external ear canals (Figure 1). Furthermore, the thorax was very small (chest circumference $19.5 \mathrm{~cm}-5 \mathrm{~cm}$ below $3 \mathrm{rd}$ centile) and there was arthrogryposis in all joints of the upper limbs, with some webbing in the elbows.

She was cyanotic, but intubation was impossible due to the upper airway obstruction caused by extreme 
micrognathia and relatively large tongue. Because of other congenital anomalies it was decided to refrain from further intervention. The girl died shortly after.

A post-mortem skeletal survey showed complete absence of ossification of all ribs (Figure 2), and no other abnormalities. The karyotype ( 650 bands level) was normal female $(46, X X)$; in particular; no changes were visible at chromosome 12 and $14 q 32$ (see Discussion). Autopsy confirmed the absence of any rib ossification; there were no rib gaps or other discontinuities in the ribs; the ribs were present as fibrous tissue. The lungs were hypoplastic (weight $10 \mathrm{~g}$; normal weight at 34 weeks 5 days, $30-35 \mathrm{~g}$ ). Besides a malrotation of the coecum no other internal anomalies were detected. Brain autopsy gave completely normal results. Careful section of the region where the inner ears were expected failed to show any remnants, indicating complete agenesis. The muscular tissues of the upper extremities appeared normal.

The parents did not show any major dysmorphic symptom, and had normally shaped chests. In both, an $X$-ray of the thorax was normal.

\section{Discussion}

The symptoms in the propositus are unusual. In our opinion they seem best to fit CCMS, although complete absence of ossification of all ribs has not been described before in these circumstances. However, the rib-gap

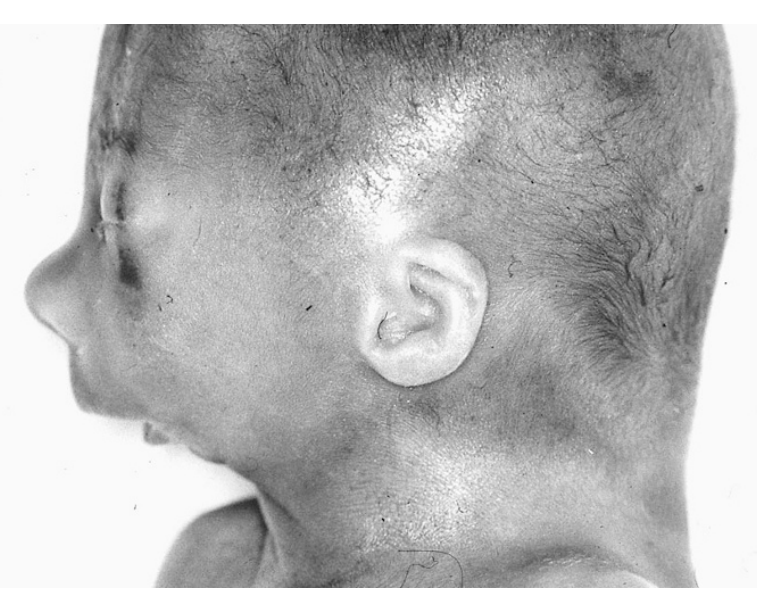

Figure $1 \mathrm{~L}$ ateral view of the proband post mortem, showing expressed retrognathia, and absence of the external ear canals defects in CCMS can vary considerably, from a few affected dorsal rib segments to only four ossified ribs. ${ }^{3}$ On the other hand, it is possible that the propositus has a hitherto undescribed condition that only resembles CCMS.

The unossified ribs and severe micrognathia in combination with the relatively large tongue and

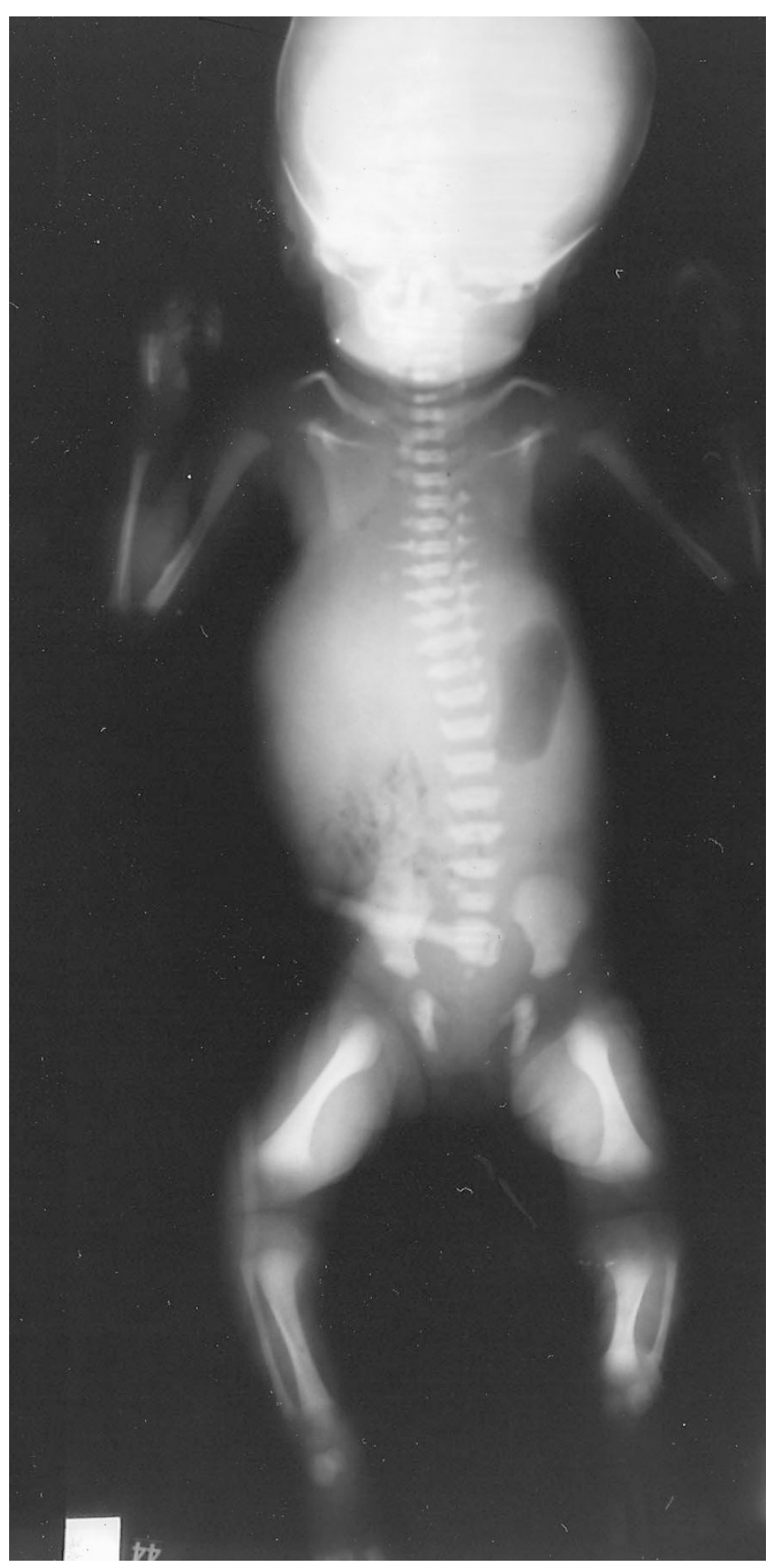

Figure 2 Babygram of the proband, showing complete absence of ossification of the ribs 
hypoplastic lungs in our opinion are sufficient to account for the respiratory distress in the present case. The pulmonary hypoplasia is probably secondary to the absence of an ossified thoracic cage preventing normal respiratory movements in utero.

There is also some resemblance to the entity described by Seghers ${ }^{4}$ and Flannery, ${ }^{5}$ with an imperforate oropharynx, and costo-vertebral and ear anomalies. H owever, the absence of rib gaps, the presence of an imperforate oropharynx, and the more expressed vertebral anomalies allow differentiation. The absence of the external ear canals and inner ears is unusual in CCM S, but has been reported. ${ }^{6} \mathrm{~N}$ ormal brain anatomy has been found before in CCMS and is indicative of a secondary cause of the developmental delay in CCMS.

The cause of CCM S is unknown. B oth an autosomal recessive $^{7-10}$ and autosomal dominant ${ }^{6,11,12}$ pattern of inheritance has been described. No case has been described with a chromosome anomaly.

A literature search for developmental genes that, mutated, may fit CCM S, showed several candidates, of which two deserve more extensive attention: myogenic factor 5 (M yf5) and the goosecoid gene.

Myf5 is one of the basic helix-loop-helix (bHLH) transcription factors, which play an important regulatory role in the development of skeletal muscles. ${ }^{13}$ The group includes M yoD, myogenin, $M$ yf5 and $M$ yf6. $M y o D$ and $M y f 5$ are structurally and functionally strongly related. It has been speculated that both might have duplicated from a common ancestor, with later diversification of their activity in different parts of the embryo. ${ }^{14}$ The human Myf5 has been mapped on chromosome12. ${ }^{15}$

The various bHLH proteins have each a distinct spatio-temporal expression in myogenesis. ${ }^{13,16} \mathrm{M}$ yf5 has a major early role in the determination of the muscle precursor cells. In a series of excellent experiments, B raun et $\mathrm{al}^{17}$ have shown that mice lacking $M$ yf5 died because of absence of the major distal part of the ribs, and furthermore, in these mice the appearance of muscle precursor cells was delayed by several days. The mice formed essentially normal muscles thereafter, indicating that $\mathrm{M}$ yf5 is dispensable. The same group of authors has suggested that the most likely explanation for the defective rib formation is that the early muscle precursor cells may provide a permissive environment for sustaining continued proliferation of rib anlage. ${ }^{18}$

The goosecoid gene is a homeobox containing gene that has been isolated in amphibia, zebra fish, chicken, mouse, and man. ${ }^{19}$ The human gene has been mapped to chromosome $14 q 32.1{ }^{19}$ In mice, goosecoid is biphasic in development: in the early phase it is involved in the process of gastrulation in the developing primitive streak: ${ }_{i}^{20}$ in the later phase it is involved in the spatial programming in discrete embryonic fields, especially the head mesenchyme and the limb buds. ${ }^{21}$ I n knockout mice it was found that the mice had multiple congenital anomalies involving predominantly the mandible, the nasal cavity and nasal pits, the inner ear, the external meatus, and the sternum and ribs. ${ }^{22,23}$ Some mice had rib fusions, especially between the first and second ribs; other mice had a reduced number of ribs and an abnormal attachment of the ribs to the sternum. ${ }^{23}$ A Ithough goosecoid is abundantly expressed in the developing limbs, the knockout mice did not show limb abnormalities.

The anomalies found in mice with a defective function of either $\mathrm{M}$ yf5 or goosecoid are not completely identical to those found in CCM S, but the overlap is of sufficient importance to urge further molecular analysis of these genes. The nature of the rib defects in goosecoid, and the combination of rib and ear anomalies in the knockout mice make goosecoid the better candidate. A $s$ the number and the size of families with CCM S is limited, direct mutation analysis seems more appropriate than linkage studies. Such studies are presently in hand.

R ecently, another interesting gene, the core-binding factor $\mathrm{Cbfal}$ was the subject of several studies and was found to be causative of cleidocranial dysostosis. ${ }^{24,25}$ Cfbal is a transcription factor of the runt family and essential for the activation of osteoblast differentiation. ${ }^{26,27} \mathrm{~K}$ nockout mice for $\mathrm{Cbfal}$ showed a complete lack of both intramembraneous and endochondral ossification. However, the clinical features in the human homologue of heterozygous loss of Cbfal, cleidocranial dysostosis, differ widely from the features in the present case, ${ }^{28}$ making it a less likely candidate gene.

In conclusion, the present case showed complete absence of ossification of ribs, micrognathia, and ear anomalies, which in our opinion are most compatible with an unusually severe expression of CCMS. The formation of the rib cage is highly dependent on M yf5. Parts of the first branchial arch and, to a lesser extent, the ribs are dependent on goosecoid. We hypothesize that mutations in goosecoid or (less likely) M yf5 may have a causal role in CCM S. Further molecular studies are needed to evaluate this hypothesis. 


\section{References}

1 Smith DW, Theiler K, Schachenmann G : R ib-gap defect with micrognathia, malformed tracheal cartilages, and redundant skin: a new pattern of defective development. J Pediatr 1966; 69: 799-803.

2 M einecke P, Wolff G, Schaefer E: Cerebro-costo-mandibular syndrome without cerebral involvement in a four year old boy. M schr K inderheilkd 1987; 135: 54-58.

3 Plotz FB, Van Essen AJ, Bosschaart A N, B os A P: The cerebro-costo-mandibular syndrome. Am J M ed Genet 1996; 62: 286-292.

4 Seghers $\mathrm{MJ}$ : Une malformation rate: l'imperforation oropharyngienne. A cta Paediatr Belgica 1996; 20: 130-137.

5 Flannery D B : Syndrome of imperforate oropharynx with costovertebral and auricular anomalies. A m J M ed G enet 1989; 32: 189-191.

6 Van den Ende JJ, Hamel BCJ, Bergman KA: Cerebrocosto-mandibular syndrome in 2 children and their mother. Proc E urop M eeting on D ysmorphol Stoll C, and Frijns J P, editors. Strasbourg. 1995; 6: 12.

$7 \mathrm{M} \mathrm{CN}$ icholl B et al.: Cerebro-costo-mandibular syndrome. A new familial development disorder. Arch Dis Child 1970; 45: 421-424.

8 Trautman M S, Schelley SL, Stevenson DK: Cerebrocosto-mandibular syndrome: a familial case consistent with autosomal recessive inheritance. J Pediatr 1985; 99: 990-991.

9 Hennekam RCM et al.: The cerebro-costo-mandibular syndrome: third report of familial occurrence. Clin $\mathrm{G}$ enet 1985; 28: 118-121.

10 D rossou-A gakidou V, A ndreou A, Soubassi-G riva V, Pandouraki $M$ : Cerebro-costo-mandibular syndrome in four sibs, two pairs of twins. J Med Genet 1991; 28: 704-707.

11 Leroy JG, Devos EA, Vanden Bulcke LJ, Robbe NS: Cerebro-costo-mandibular syndrome with autosomal dominant inheritance. J Pediatr 1981; 99: 441-443.

12 Merlob $\mathrm{P}$ et al.: Autosomal dominant cerebro-costomandibular syndrome: ultrasonographic and clinical findings. A m J M ed G enet 1987; 26: 195-202.

$13 \mathrm{O}$ Ison EN, K lein WH: bHLH factors in muscle development: dead lines and commitments, what to leave in and what to leave out. G enes D evelop 1994; 8: 1-8.

14 Cossu G, Tajbakhsh S, B uckingham M : H ow is myogenesis initiated in the embyro?. TIG 1996; 12: 218-223.
15 Braun T, Grzeschik KH, Bober E, A rnold H H : The M yf genes, a group of human muscle determining factors, are located on different human chromosomes. Cytogenet Cell G enet 1989; 51: 969.

16 Rong PM, Teillet MA, Ziller C, Le Douarin NM: The neural tube/notochord complex is necessary for vertebral but not limb and body wall striated muscle differentiation. D evelopment 1992; 115: 657-672.

17 Braun T, R udnicki M A, A rnold A A, Jaenisch R : Targeted inactivation of the muscle regulatory gene $M$ yf- 5 results in abnormal rib development and perinatal death. Cell 1992; 71: $369-382$

18 Rudnicki MA et al.: M yoD or M yo- 5 is required for the formation of skeletal muscle. Cell 1993; 75: 1351-1359.

19 Blum M et al: M olecular cloning of the human homeobox gene goosecoid (GSC) and mapping of the gene to human chromosome 14q32.1. G enomics 1994; 21: 388-393.

20 Blum $M$ et al.: Gastrulation in the mouse: the role of the homeobox gene goosecoid. Cell 1992; 69: 1097-1106.

21 Gaunt SJ, Blum M, De Robertis EM: Expression of the mouse goosecoid gene during mid-embryogenesis may mark mesenchymal cell lineages in the developing head, limbs, and ventral body wall. Development 1993; 117: 769-778.

22 Yamada $G$ et al.: Targeted mutation of the murine goosecoid gene results in craniofacial defects and neonatal death. Development 1995; 121: 2917-2922.

23 Rivera-Perez JA et al.: Goosecoid is not an essential component of the mouse gastrula organizer but is required for craniofacial and rib development. Development 1995; 121: 3005-3012.

$24 \mathrm{O}$ tto $\mathrm{F}$ et al.: Cbfa1, a candidate gene for cleidocranial dysplasia syndrome, is essential for osteoblast differentiation and bone development. Cell 1997; 89: 765-771.

$25 \mathrm{M}$ undlos $\mathrm{S}$ et al.: $\mathrm{M}$ utations involving in the transcription factor CBFA 1 cause cleidocranial dysplasia. Cell 1997; 89: 773-779.

26 Komor $\mathrm{T}$ et al.: Targeted disruption of $\mathrm{Cbfal}$ results in a complete lack of bone formation owing to maturational arrest of osteoblasts. Cell 1997; 89: 755-764.

27 Rodan GA, Harada S: The missing bone. Cell 1997; 89: 677-680.

28 Jensen BL: Somatic development in cleidocranial dysplasia. A m J Med Genet 1990; 35: 69-74. 